\title{
NOTA
}

\section{Mario Vargas Llosa entre la política y la literatura}

\author{
NÉCKER SALAZAR \\ Universidad Nacional Federico Villarreal \\ neckerunfv@yahoo.es
}

Recibido: 19/9/14 Aceptado: 28/10/14 Publicado on line: 10/2/15

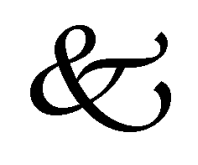

Los estudiosos de la obra de Mario Vargas Llosa se han ocupado, normalmente, de analizar su obra de creación, ya sea sus novelas, cuentos y obras de teatro, atendiendo, obviamente, a su novelística. Sin embargo, no suelen abordar su producción de no ficción, es decir, sus ensayos, discursos, memorias, artículos y reportajes. La lectura de estos textos es de mucha utilidad para conocer su pensamiento, sus ideas sobre la literatura, la política, el arte, la cultura y su posición como intelectual frente a la sociedad contemporánea, entre otros temas.

El último libro de ensayos de Jorge Valenzuela ${ }^{1}$, precisamente, analiza este tipo de textos a partir de uno de los puntos que puede muy bien caracterizar la producción literaria de Vargas Llosa: las relaciones entre la política y la literatura. Conformado por cuatro ensayos, el libro problematiza las relaciones existentes entre el campo literario y las demandas que lo afectan desde el campo político. Para ello, el crítico y escritor peruano realiza un agudo análisis de las ideas que expone el célebre novelista en torno a aquellas relaciones, en textos publicados desde los años sesenta. Nos referimos al discurso "La literatura es fuego" (1967), el estudio García Márquez. Historia de un deicidio

1 Jorge Valenzuela Garcés. Principios comprometidos. Mario Vargas Llosa entre la literatura y la política. Lima, Cátedra Vargas Llosa, Cuerpo de la metáfora editores y Facultad de Letras y Ciencias Humanas de la Universidad Nacional Mayor de San Marcos, 2013; 128 pp. 
(1971), sus memorias El pez en el agua (1993) y el reportaje Diario de Irak (2003).

En el primer ensayo, el autor analiza la formación del campo intelectual que tiene lugar en los años sesenta, campo que es decisivo en "la figura del compromiso" y en "la escritura de novelas totales" (p. 11), en las que se plasma una visión integral del proceso social e histórico de la realidad del continente latinoamericano. Valenzuela parte de las reflexiones de Pierre Bourdieu sobre el "campo literario" en el sentido de que la legitimación del escritor y su proyecto escritural, vía la crítica y la institución literaria, articula las relaciones entre el escritor y sus proyectos con la sociedad a través de la demanda social. Queda claro que en el "campo literario" es fundamental el sentido público del texto, el mismo que se relaciona con el sentido colectivo de la verdad.

El particular contexto en que se desarrolla el proyecto de "la novela total" en Latinoamérica se caracteriza por una demanda de compromiso con la causa del socialismo, actitud que encuentra en la novela el cauce de su materialización, por lo que el boom se propone, en esa línea, dar respuesta a la urgencia de escribir ficciones que aborden el problema del ser latinoamericano y su proyecto de liberación continental. Este momento está marcado por la intervención del campo político sobre el campo literario a raíz del impacto que tiene la Revolución Cubana sobre el proyecto identitario latinoamericano y el destino del continente. Estos factores, de acuerdo con Valenzuela, "configuran el perfil del llamado intelectual de izquierda comprometido con el socialismo" (p. 16).

En la búsqueda de una América libre y moderna, el campo intelectual afirma los lazos entre la política y la literatura, cuya relación consolida la imagen del intelectual comprometido. Siguiendo las ideas de Paul Baran, Valenzuela afirma que la función del intelectual, en ese momento, debe, entre otras acciones, propiciar el entendimiento de las relaciones que existen en el conjunto social. En el pensamiento de Baran, influido por el pensamiento hegeliano marxista, la verdad es la totalidad que se traduce en "la posibilidad de representar el mundo en todas sus fases" (p. 23). Es tarea, entonces, del intelectual, identificar en el sistema capitalista el mecanismo que busca desintegrar y desarticular la experiencia social y, en oposición, reconstruir y articular los componentes de la totalidad integrante del proceso histórico, en el cual el arte, la cultura y la literatura son parte conformante.

Caracterizada, de otro lado, por su particular temporalidad, por la superación de la narración lineal, por la forma como desarrolla la representación de los diversos niveles de la realidad y la exploración de novedosas estructuras narrativas, entre otros elementos, la novela moderna hispanoamericana se propone lograr la representación total de la realidad. Como explica Valenzuela, ese es el propósito del boom, entre cuyas muestras novelísticas figuran $\mathrm{La}$ 
casa verde, Cien años de soledad y Rayuela, tres novelas orientadas a captar la totalidad. En dicho contexto, "el mejor ejemplo de ese intento totalizador para Vargas Llosa es la gran novela de García Márquez” (p. 33-34), lo que se explica porque desarrolla un ciclo completo, aborda los diversos planos que comprende el mundo representado y tiene una particular estructura. En el libro de crítica García Márquez. Historia de un deicidio, el novelista afirma que Cien años de soledad se basa en la dialéctica hegeliana ya que reconstruye personajes, fragmentos y hechos presentados en sus obras anteriores para ofrecer una unidad estructurada, una "síntesis superior" que trata de plasmar en su novela más emblemática. Para Vargas Llosa, la "totalidad de la novela" se logra con la historia completa de un mundo desde su fundación hasta su desaparición, la representación de los sectores sociales, la caracterización de los roles de los personajes y su configuración en términos de oposición. Lo mágico, lo fantástico, lo milagroso y lo mítico-legendario cumplen roles esenciales en la novela.

Finalmente, en el análisis de Valenzuela, el proyecto de novela total en el continente "no se concibe sin la existencia de la figura del intelectual comprometido" (p. 41). En esta exigencia, la novela de García Márquez se erige como la mayor expresión de la novela total, en la que el intelectual comprometido, asumiendo la dialéctica hegeliana y buscando la verdad, tiene un acercamiento a la realidad en todos sus niveles posibles captados mediante lo imaginativo y lo real objetivo.

El segundo ensayo del libro estudia la forma como Vargas Llosa construye "la imagen del héroe intelectual a partir de la figura del poeta Carlos Oquendo de Amat" (p. 45). El texto analizado es el conocido discurso "La literatura es fuego", leído por el novelista cuando recibió el Premio Rómulo Gallegos en 1967. En esa década, se forma el intelectual de izquierda, ligado a un pensamiento ideológico socialista, la adscripción a las ideas de Marcuse y Sartre, e identificado con los ideales de la Revolución Cubana. Para Valenzuela, las ideas de Baran nos permiten comprender el pensamiento que el novelista expone en dicho discurso. Así, para Vargas Llosa, "existen obstáculos que impiden un orden más humano", "el intelectual debe realizar una crítica despiadada" frente a todo lo existente, y debe ser "un agitador, un utópico, un subversivo" (p. 49). Esta línea se halla en diálogo con las ideas del novelista, en particular cuando afirma que el escritor representa un pensamiento crítico o cuando sostiene que la literatura es una "insurrección permanente". De este modo, los intelectuales ingresan a formar parte de los defensores del ideal revolucionario y contribuyen en la construcción del camino a la revolución como un hecho posible. Vargas Llosa es consciente del papel del intelectual y de la vocación del escritor, pero también de las tensiones que pueden 
producirse cuando no coinciden esos dos aspectos. Aun así, para el novelista, esa misma contradicción debe ser un "desgarramiento" para producir auténtica literatura. Durante los años sesenta, y tomando en cuenta la posición política de los intelectuales del continente, Oquendo se convierte en el paradigma del intelectual y del escritor comprometido pues en él coinciden el pensamiento crítico y el ejercicio libre de la literatura. Su figura se afirma como ejemplo en virtud de su activismo político en el contexto de la vanguardia política y como un exponente de la "modernización literaria", aspectos que bien se pueden apreciar en la personalidad del mismo novelista, por lo que la valoración de Oquendo puede ser también la propia definición que Vargas Llosa hace de sí mismo.

Valenzuela hace eco de las ideas de Ángel Rama en el sentido de que el escritor debe ser crítico frente a las limitaciones que la sociedad impone a su oficio y consciente de los efectos que su obra puede producir en el proceso social. En esa línea, en el citado discurso, Vargas Llosa ahonda en las condiciones sociales y económicas en que se desarrolla el trabajo del escritor y, que, en la realidad latinoamericana, no suelen ser favorables a la creación, como sucedió con Oquendo, quien enfrentó el atraso social y el rechazo social. El sentido de su persistencia como poeta resulta emblemático, puesto que dichas condiciones no anularon la llama de su creación, lo que afirma aún más su "heroicidad intelectual". Para Valenzuela, la semblanza de Oquendo lo proyecta como creador visionario, pese a ser un "doble marginal", puesto que "produce poesía cuyo consumo social es muy limitado" y, además, es un "poeta cuya estética, respecto de la escuela dominante, también resulta siendo marginal” (p. 56). Para Valenzuela, Oquendo es elegido por Vargas Llosa para demostrar que la modernidad literaria que encarna es equivalente a la permeabilidad de la literatura del boom, que también puede dialogar con la literatura de Occidente, pero no para imitarla sino para desarrollar signos de originalidad artística como se puede apreciar en la poética del autor de 5 metros de poemas. Así, el novelista incide en la valoración del universalismo de la creación literaria como en la armonización de las tradiciones nacionales y foráneas en el arte creador. Vargas Llosa también reivindica la figura heroica de Oquendo frente al ensañamiento de que fue objeto, lo que traduce la actitud de las sociedades latinoamericanas frente a sus escritores y artistas a quienes suele negar, en forma sistemática, condiciones favorables a la creación, a la vez que limita tanto el circuito editorial como la promoción de la literatura.

Por otro lado, el crítico aborda la concepción del escritor en el pensamiento de Vargas Llosa, para quien surge para expresar una insatisfacción frente a la sociedad en que le tocó vivir. La imagen de la responsabilidad del escritor, de acuerdo con Valenzuela, responde a las demandas del campo intelectual 
de esa década; por ello, no puede olvidar su función crítica ni alejarse de su rol como sujeto con capacidad para agitar, cuestionar y producir situaciones de cambio y de mejora social. En ese sentido, la metáfora de la literatura convertida en fuego trasluce el signo renovador de la literatura, ya que "ilustra la regeneración que el fuego lleva a cabo cuando destruye lo caduco y permite el nacimiento, gracias a la crítica, de lo puro" (p. 63). Otro punto tratado por el crítico es la imagen de la Revolución Cubana en el conocido discurso de Vargas Llosa. Las dificultades que enfrentaron tanto la patria de José de Martí como los escritores e intelectuales no impidieron, en ningún sentido, la adhesión de los escritores comprometidos a los ideales que defendía el pueblo de Cuba. El entusiasmo del novelista por estos ideales le hace avizorar el triunfo del socialismo, lo que, sin embargo, no se produjo. No obstante, esta filiación "a una fe en la que el modelo revolucionario de sociedad cubana es el paradigma, se ajusta a las esperanzas de los escritores intelectuales de izquierda de la época" (p. 71).

El tercer ensayo del libro discute la vigencia del paradigma del escritor comprometido que Vargas Llosa representa mediante los conceptos de "ética de la convicción" y "ética de la responsabilidad" propuestos por Max Weber. Pero sobre todo estudia el cambio de posición de Vargas Llosa respecto a la condena que realizó a la ocupación norteamericana a Irak el año 2003 y las falacias a las que apela para justificar dicha invasión. En este ensayo, el texto tomado como base para el estudio es el reportaje Diario de Irak. Valenzuela plantea que, si bien Vargas Llosa mantiene su condición de escritor comprometido, su modelo ha dejado de ser sartreano y ha optado, más bien, por el paradigma liberal. Basándose en las ideas de Mark Lilla y Raymond Aron, el crítico subraya las limitaciones de la concepción de Sartre sobre el escritor comprometido, además de cuestionar su posición por ser discutible. Frente a ello, valora el deber moral del intelectual que, actuando con independencia, asume una determinada actitud frente al sistema político y la injusticia.

En la lectura de Valenzuela, queda claro que Vargas Llosa enfrenta serios "riesgos" cuando cree realizar un "análisis certero" de la situación en Irak, por lo que resulta criticable "la creencia de que, asumiendo beligerantemente o cambiando una posición por otra es como se solucionan los problemas en el ámbito de la política" (p. 81). El radical cambio del novelista sobre la invasión a Irak lo lleva a pasar de criticarla a realizar su justificación en una distancia de pocos meses. El viaje que emprende a dicho país para analizar la situación de la realidad iraquí durante la ocupación tiene por finalidad "avalar" su rectificación. Su modo de persuadir considera que, con su reportaje, realizará un juicio más "certero" y logrará ser más "objetivo"; por consiguiente, desde su lógica de razonamiento, "cree en la posibilidad de corregir sus juicios políticos 
si reconoce previamente el error en el que cree haber incurrido" (p. 83). Este modo de operar evidencia que su pensamiento se halla en la esfera de la "ética de la convicción", posición que revela las fisuras de su discurso y de su actitud como intelectual.

El novelista justifica la invasión norteamericana a Irak basándose en testimonios y conversaciones, en los cuales resulta sintomático que las personas "estén de acuerdo con la intervención en Irak" (p. 84). Llama la atención que apele a la técnica literaria en la presentación de los personajes, con lo que busca conseguir una imagen "singular" que favorece la impresión sobre el pueblo iraquí que quiere transmitir a los lectores. La realidad que enfatiza es el desorden que se observa en el pueblo, lo que, según Valenzuela, "porta un contenido ideológico importante: los iraquíes, al estar siempre sumidos en una dictadura, no saben cómo comportarse en libertad" (p. 85). Desde este punto de vista, Vargas Llosa postulará que será necesario que conozcan la "libertad de Occidente”. Además, el reportaje no oculta la condición del novelista como sujeto occidental, lo que proyecta una representación del pueblo iraquí desde la ajenidad cultural y lo extraño, lo que, a su vez, trastoca los propios valores de la cultura iraquí.

El crítico evidencia las estrategias discursivas empleadas por el novelista identificando las falacias, y sus funciones argumentativas, a las que apela para realizar su autopresentación como escritor, así como para justificar la ocupación norteamericana. Vargas Llosa quiere "disminuir" su imagen de escritor conocido recurriendo "a la piedad o a la clemencia para conseguir la aprobación de una conclusión o la legitimación de un pedido” (p. 86). Igualmente, en forma muy inteligente, busca hacer creer a los lectores que su viaje y estadía en Irak garantizan la objetividad y el valor irrefutable de sus juicios, con lo que quiere derivar de una supuesta causa una conclusión que no guarda necesariamente relación lógica con dicha premisa. Esta estrategia espera lograr "la aceptación de la demanda de adhesión de los lectores a lo que Vargas Llosa considera central, es decir, la condena de la dictadura de Sadam Hussein". De esta manera, "la justificación de la invasión norteamericana a ese país queda legitimada por el viaje y su producto" (p. 87).

Valenzuela plantea que la idea del intelectual comprometido "es un paradigma disfuncional en el análisis del presente” (p. 88). Contrastando la "ética de la convicción", en la que el intelectual no asume su responsabilidad, y la "ética de la responsabilidad", que alude, en cambio, a su capacidad de asumir las consecuencias de sus actos, para el crítico, el pensamiento de Vargas Llosa postula "la desaparición de la ética de la responsabilidad" (p. 90), por lo que la posibilidad de este tipo de ética para el novelista es "nula". La justificación de la ocupación de Irak realizada por el escritor considera la 
naturaleza vesánica y corrupta de la dictadura de Hussein, la limitación de la "soberanía" del pueblo iraquí mediante la imposición de una política de terror que restringe la capacidad de respuesta de los iraquíes y el hecho de que la ocupación de Irak significa "la posibilidad de que ese país rompa con el círculo vicioso del autoritarismo y totalitarismo" (p. 91). No obstante, lo que propone Vargas Llosa revela un marcado trasfondo ideológico que sobredimensiona el papel de Estados Unidos como país autoconsiderado protector y vigilante de la democracia y la libertad, bajo cuya ocupación, según el novelista, terminarán el autoritarismo y el totalitarismo. Sin embargo, esta "moral de la convicción" legitima el uso de la fuerza y la violencia, a la vez que fortalece la hegemonía política y económica del país del norte. El ensayo demuestra que Vargas Llosa asume una posición contradictoria, dogmática y ambigua, que se halla en abierto desafío a la "ética de la responsabilidad", lo que se agrava aún más dado que enarbola supuestamente principios libertarios y de defensa de la sociedad.

El cuarto ensayo del libro analiza, en primer término, los procedimientos de legitimación política a los que apela Vargas Llosa en El pez en el agua; luego, la forma en que se realiza la plasmación de los recuerdos personales del novelista y la manera como son abordados el miedo y la derrota en el libro. Valenzuela considera que las memorias instituyen una dinámica en la que el "yo" se halla en relación con el pasado pero a partir de un vínculo con los "demás", frente a quienes busca presentarse y explicar y justificar los hechos. En dicho proceso de constitución del "yo", se realiza "un ejercicio de reflexión y evocación" que se plantea "la tarea de legitimarse ante los demás y reconstruir una parte de su pasado para darle una forma coherente mediante el despliegue de un conjunto de estrategias como la recuperación de imágenes, o procedimientos como la analogía o la comparación" (p. 98). Distingue a las memorias el estar marcadas por las circunstancias, el ser un estado temporal, momentáneo, frente al carácter definitivo y total de la autobiografía. Decir la verdad en las memorias confronta dicho desafío con la situación personal del escritor, ya que este expresa "sus debilidades y sus contradictorias aproximaciones al pasado, pues en el tratamiento de los recuerdos es imposible abandonar esa dosis de subjetividad con que se experimenta la vida, sobre todo cuando ese yo que recupera sus recuerdos, además de disolverse en los demás para explicarse a sí mismo, viene de sufrir una derrota, como es el caso de Vargas Llosa” (p. 100).

Al publicarse El pez en el agua como libro de memorias en 1993, el autor hizo alternar, en la crónica política sobre su derrota en las elecciones presidenciales de 1990, la narración de sus recuerdos familiares, con lo que la estructura final del texto logró conseguir mayor eficacia literaria. Permeadas por lo político, las memorias revelan el "proyecto nacional que porta Vargas Llosa a través de 
sus ideales liberales, y otro estrictamente familiar [...] cuya función es servir [...] como marco moral a las acciones políticas del autor" (p.103). Valenzuela observa que la organización de las memorias sigue un tránsito del pasado al presente, ya que las dos partes que conforman el texto abarcan periodos importantes de la vida del novelista (1946-1957 y 1987-1990), marcados por su viaje a Europa y su reencuentro con la escritura. De igual relevancia son las precisiones hechas por el crítico sobre los procedimientos de técnica literaria con que el novelista desarrolla el tratamiento de sus recuerdos y la mostración de su drama personal. Estos procedimientos se refieren al predominio de la narración, la presentación de acciones violentas, el énfasis en el carácter drástico de la intercalación de episodios, el desarrollo de la trama de cada parte basado en el eje problema-resolución y el orden causalista de los eventos que conforman la narración. Para Valenzuela, el plano temporal es fundamental como parte de la estrategia de Vargas Llosa, ya que, partiendo del momento desde el que enuncia y considerando el pasado que recupera, busca explicarse los acontecimientos del presente, asumir su ubicación frente a los otros y justificar su fracaso. La intriga que construye opera con el propósito de presentarse como víctima en el entramado de las acciones y como afectado por el entorno político, por lo que tanto el pasado como el presente "dan cuenta de una vida marcada por hechos violentos que supusieron un despojo de su propia individualidad" (p. 106). En ese contexto, los vasos comunicantes instauran filtraciones entre los dos momentos de la vida del novelista. Frente al impacto de dichas circunstancias, la familia de los Llosa actuará como "único refugio" para el escritor. Estos procedimientos son pensados inteligentemente por el novelista y tienen "un efecto psicológico", pues le permiten comprender su derrota, le dan la posibilidad de procesar su angustia y de proponer su propia redención.

Las memorias, en otro plano, revelan la estrategia seguida por el autor para legitimar su ideología liberal y su actuación política. Siguiendo a Teun van Dijk, Valenzuela explica que la legitimación es "un acto social", que adquiere la condición de "una respuesta discursiva". Así, El pez en el agua se instituye como una defensa de la propia condición de la persona mediante un acto de habla que ofrece razones o motivaciones por acciones realizadas en el pasado. En su libro, el autor defiende "el carácter absolutamente honesto de su desempeño político durante la campaña hacia la presidencia y la legitimidad de su proyecto de modernización nacional" (p. 112). Dicha defensa se circunscribe en una dimensión ética, ya que las memorias quieren denunciar "una situación caracterizada por su defectividad”, que se expresó en las incoherencias de sus propios seguidores al actuar en contra de los principios más elevados de la filosofía liberal. Esta posición busca una legitimación del autor como un hombre 
respetuoso del Estado de derecho y la ley, lo que resulta sintomático, ya que "refuerza" su imagen como crítico del Perú cuando sostiene que "es un país pre moderno en el que, precisamente, por no respetar la ley, se ha instalado la barbarie" (p. 115). Ideológicamente, esta estrategia busca posicionar al movimiento liderado por el novelista como representante de la modernidad, la libertad y la honestidad.

Para Valenzuela, El pez en el agua testimonia el conflicto vivido por el autor que se vincula con la amarga experiencia de la derrota en la política y el miedo vivido en la época de la infancia y la adolescencia causado por la figura paterna. Sobre su derrota, el novelista sostiene que su fracaso en la política obedece a las condiciones del sistema político del país y al hecho de que su propuesta liberal no fue valorada como él esperaba. Como la derrota es "uno de los sucesos más difíciles de aceptar" (p. 120), se empeña en realizar una justificación asumiendo que ello fue producto de la impericia y los yerros de quienes estuvieron en su entorno, a lo que se suma su condición de falsos liberales. No obstante, el novelista procesa el fracaso orientándolo con un fin dinámico, lo que da lugar a otro momento importante de su destino personal. Respecto del miedo, este sentimiento se asocia también al fracaso y es originado por la figura del padre, con quien el autor mantuvo una relación tirante y de odio, lo que explica la "reivindicación" de los Llosa y su presentación como familia virtuosa. La experiencia con el padre incubó en el futuro novelista "una rebeldía contra todo autoritarismo" (p. 124), lo que, igualmente, desarrolló en él un espíritu desafiante y contestatario tanto en la literatura como en la política.

Los ensayos reunidos en este libro analizan la evolución seguida por el pensamiento de Vargas Llosa desde los años en que asumió una posición de compromiso, condición que, sin embargo, devino en un paradigma que entró en crisis al diluirse en su pensamiento la "ética de la responsabilidad" y primar en sus ideas la "ética de la convicción”. Basándose detenidamente en textos no ficcionales del autor, el aporte de Valenzuela contribuye en la dilucidación de las relaciones siempre tan complejas y conflictivas entre la literatura y la política, además de demostrar el carácter contradictorio y ambiguo del célebre novelista cuando es invadido por los "demonios" que rodean el ejercicio del poder. 
